\title{
Extra-adrenal Paraganglioma: An Uncommon Cause of Secondary Hypertension in a Young Subject
}

\author{
Kota SK${ }^{1}$, Kota SK${ }^{2}$, Jammula $\mathbf{S}^{3}$, Panda $\mathbf{S}^{4}$ \\ ${ }^{1}$ Dr. Sunil Kumar Kota, DNB Resident, Department of Endocrinology, Medwin Hospital, Hyderabad-500001, Andhra \\ Pradesh, India. ${ }^{2}$ Dr. Siva Krishna Kota Department of Anaesthesia, Central Security Hospital, RIYADH, Saudi Arabia. \\ ${ }^{3}$ Dr. Sruti Jammula Department of Pharmaceutics, Roland Institute of Pharmaceutical Sciences, BERHAMPUR, Orissa, \\ India. ${ }^{4}$ Dr.Sandip Panda Department of Cardiology, Jawaharlal Institute of Postgraduate Medical Education and \\ Research, Pundicherry, India.
}

Address for correspondence: Dr. Sunil Kumar Kota, E-mail: hidocsunil@ibibo.com

\begin{abstract}
A 8 year boy was admitted with features of tuberculous meningitis. He was detected to have hypertension. Further investigations revealed an extra-adrenal paraganglioma. Tuberculous meningitis and paraganglioma could be chance associations. Paraganglioma is a rare and potentially lethal cause of secondary hypertension, very uncommon at this age. If left untreated it leads to complications arising from unrelenting hypertension. We report a case report on this very rare disease of paraganglioma presenting in an unexpected way.
\end{abstract}

Key words: Paraganglioma, Tuberculous meningitis, Secondary hypertension

\section{Introduction}

The paraganglion system is formed by numerous collections of neuroepithelial cells ${ }^{1}$. Paraganglioma are tumors of paraganglia. The most common site is adrenal medulla, where it is known as pheochromocytomas. Those located outside the adrenal gland as extra-adrenal paragangliomas (EAPs). They have a more aggressive course than their adrenal counterparts. The diagnosis of pheochromocytomas and paragangliomas provide a potentially correctable cause of hypertension, and their removal can prevent lethal hypertensive crises.

\section{The Case}

\section{!Unexpected End of Formula}

A 8-year-old boy was admitted with fever, headache, and vomiting of 1 month duration. In the past, he had occasional headache relieved by medicines. There was no significant illness in the family. On examination patient appeared sick, pulse rate was 110/ minute being felt at all limbs, BP was $210 / 130 \mathrm{mmHg}$ in the supine position without any asymmetry in limbs and postural drop. He had signs of meningeal irritation without focal neurologic deficits. Investigations revealed hemoglobin $13.8 \mathrm{~g} \%$, total leukocyte count $13,400 / \mathrm{mm}^{3}$ with polymorphs $75 \%$ and lymphocytes $23 \%$. His blood sugar, renal function tests, liver function tests, and serum electrolytes were within normal limits. Cerebrospinal fluid analysis revealed lymphocytic pleocytosis in the cerebrospinal fluid with protein content of $134 \mathrm{mg} \%$ and sugar of $90 \mathrm{mg} \%$ (corresponding blood sugar 85 $\mathrm{mg} \%$ ). Computed tomography (CT) brain showed sulcal effacement. Ultrasonography abdomen showed a well-defined hypodense area in the epigastric region. Electrocardiogram and X-ray chest were normal. Twentyfour hour urinary Vanilmandelic acid (VMA) (35 mg/ 24 hrs, normal: $2-7 \mathrm{mg} / 24 \mathrm{hrs}$ ) and urinary metanephrines levels $(2560 \mu \mathrm{g} / 24 \mathrm{hrs}$, normal: 140-760 $\mu \mathrm{g} / 24 \mathrm{hrs})$ were elevated. Contrast enhanced CT abdomen showed soft tissue mass of $4.5 \times 2.9$. $\times 3.5$ in the left paraaortic region with heterogenous enhancement (Figure 1). Minimal compression was noted in the inferior vena cava with preserved fat plane. There was no lymph node enlargement with normal adrenals and renal arteries. The possibility of aortosympathetic paraganglioma was entertained. Establishing a diagnosis of tuberculous meningitis with EAP, he was prescribed antituberculous drugs, a blockers followed by $ß$-blockers and calcium 


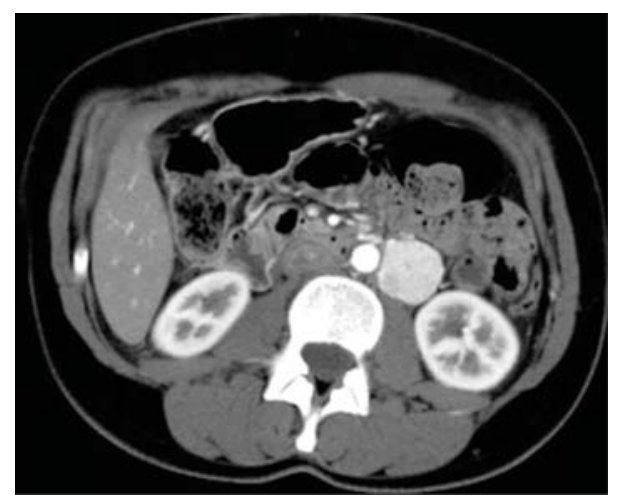

Fig 1: CT scan abdomen showing soft tissue mass of $4.5 \times 2.9 . \times 3.5$ in the left paraaortic region with heterogenous enhancement

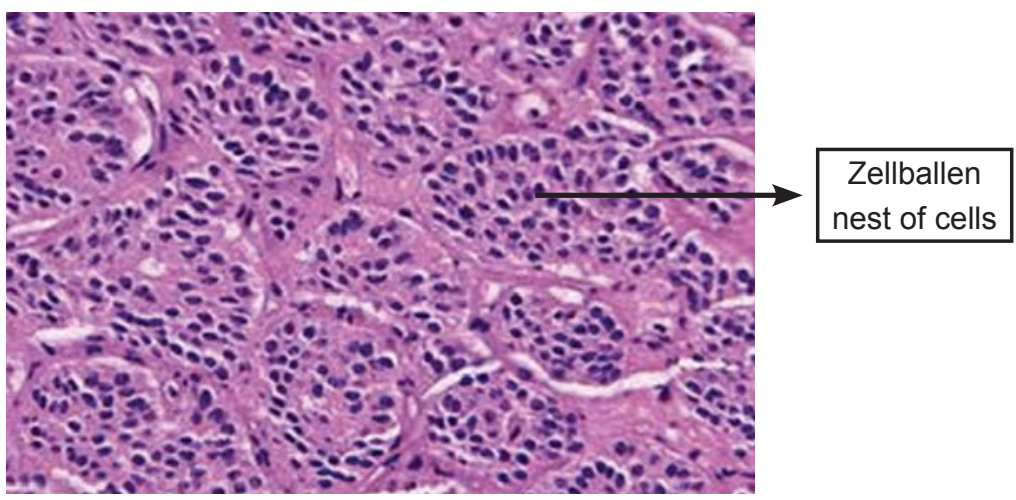

Fig 2: Histology of the biopsied specimen revealing characteristic organoid or zellballen nest of cells (hematoxylin-eosin stain, original magnification X 300) channel blockers. Three weeks later, with proper BP control, the mass was surgically resected. Biopsy of the specimen revealed characteristic organoid or zellballen nest of cells confirming the diagnosis of paraganglioma (Fig 2). Patient was discharged after four days. One month later, patient was better without any recurrence of hypertension.

\section{Discussion}

Alezais and Peyron described extra- adrenal chromaffin tumors and called them paragangliomas in 1906. EAPs are divided into 2 categories: related to either parasympathetic or sympathetic system. The former, usually nonchromaffin, lie in the head and neck, including the carotid body, jugulotympanic, and mediastinal and aorticopulmonary paraganglia. The latter are chromaffin positive, associated with the peripheral sympathetic nervous system and secrete catecholamines. They lie in the para-axial region of the trunk close to the paravertebral and prevertebral ganglia ${ }^{2}$. Rarely, paragangliomas have been described in other unusual sites, such as the gallbladder, mesentery, kidney, and prostate ${ }^{3}$.

Incidence of all EAPs is 2-8 per million. EAPs

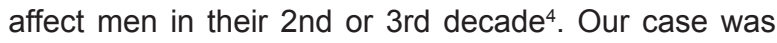
unique in its presentation in the first decade itself. EAPs can be inherited as an isolated autosomal dominant trait or as part of the multiple endocrine neoplasia type II syndromes, neurofibromatosis and von HippelLindau disease. Germ line mutations in the succinate dehydrogenase (SDH) subunit genes SDHB, SDHC and $\mathrm{SDHD}^{5}$ predispose carriers to tumors of the paraganglia.

EAPs can be nonfunctional, but infradiaphragmatic ones are functional. The lower levels of phenylethanolamine $\mathrm{N}$-methyltransferase (the enzyme responsible for the conversion of norepinephrine to epinephrine by methylation) leads to higher levels of norepinephrine. Symptoms include hypertension (paroxysmal and/or sustained), headaches, sweating, palpitations, anxiety and tremors. It can present with heart failure, pulmonary edema, arrhythmias, and intracranial hemorrhage. There are clinical differences between adrenal pheochromocytomas and EAPs. Adrenal pheochromocytomas often affect females in $5^{\text {th }}$. 7 th decades. EAPs affect males in $2^{\text {nd }}-3^{\text {rd }}$ decade ${ }^{6}$. EAPs are more likely to be multifocal than are adrenal lesions.

In our patient the clinical scenario with raised urinary VMA and metanephrines and imaging evidence gives unequivocal confirmation of the diagnosis. Urinary tests for VMA, metanephrines (total or fractionated), and catecholamines are commonly used initially ${ }^{7}$. The fractionated metanephrines and catecholamines are the most sensitive. Plasma tests include measurements of catecholamines, metanephrines, and chromagranin A. False-positive elevations occur with stress, including venipuncture, medications (levodopa, labetalol, sympathomimetics). T2-weighted magnetic resonance imaging with gadolinium contrast is somewhat better than CT for imaging extra-adrenal pheochromocytomas and paragangliomas ${ }^{8}$. A heterogeneous, hypervascular, retroperitoneal mass with areas of necrosis with typical clinical setting is highly predictive of EAPs. The organs of Zuckerkandl are the most common site of involvement for paraaortic EAP. These are located along the aorta, beginning cranial to the superior mesenteric artery or renal arteries and extending to the level of the aortic bifurcation or just beyond. The highest concentration is typically seen at the origin of the inferior mesenteric artery. The organs of Zuckerkandl are not often visualized radiologically. The close relationship of paragangliomas to the aorta may be helpful in differentiating these tumors from other primary retroperitoneal tumors. Tumors can also be localized using radioactive tracers, 
including $\mathrm{I}^{131}$ or $\mathrm{I}^{123}$ metaiodobenzylguanidine (MIBG), $\mathrm{In}^{111}$ - somatostatin analogs. However, there is a $10 \%$ false-negative rate with MIBG scanning. Most malignant tumors show an enhanced glycolytic metabolism with increased uptake of deoxyglucose that can be visualized by PET using 18F]2- fluoro- -2-deoxyglucose (FDG) ${ }^{9}$.

Complete tumor removal is the ultimate therapeutic goal. Preoperatively a blockers (phenoxybenzamine) should be initiated at low doses with gradual increment. Oral prazosin or intravenous phentolamine can be used to manage paroxysms, while awaiting adequate a-blockade. ß-Blockers are added after adequate $\alpha$ blockade (10-14 days) and increased if tachycardia persists. Calcium channel blockers or angiotensinconverting enzyme inhibitors are used in cases of inadequate BP control ${ }^{10}$. Blood pressure can be labile during surgery, particularly at the onset of intubation or when manipulating the tumor. Nitroprusside infusion is useful for intraoperative hypertensive crises, and hypotension usually responds to volume infusion. No such complication was noted in our patient.

\section{References}

1. Archontovasilis $\mathrm{F}$, Markogiannakis $\mathrm{H}$, Dikoglou C, Drimousis P, Toutouzas KG, Theodorou D, et al. Paraganglioma of the greater omentum: Case report and review of the literature. World J Surg Oncol 2007;5:87.

2. Lack EE. Tumors of the adrenal gland and extra adrenal paraganglia. In: Atlas of Tumor Pathology, $3^{\text {rd }}$ Series, fascicle 19. Washington, DC: Armed forces institute of Pathology, 1997:265-385.

3. Mikhail RA, Moore JB, Reed DN, Abbott RR. Malignant retroperitoneal paragangliomas. J Surg Oncol. 1986;32:32-6.
4. BennDE, Gimenez-RoqueploAP, Reilly JR, Bertherat J, Burgess J, Byth K, et al. Clinical presentation and penetrance of pheochromocytoma/paraganglioma syndromes. J Clin Endocrinol Metab. 2006;91:82736.

5. Timmers HJ, Kozupa A, Eisenhofer G, Raygada M, Adams KT. Clinical presentations, biochemical phenotypes and genotype phenotype correlations in patients with SDH B associated pheochromocytoma and paraganglioma. J Clin Endocrinol Metab. 2007; 92:7:79-86.

6. Neumann HP, Pawlu C, Peczkowska M, Bausch B, McWhinney SR, Muresan M, et al. EuropeanAmerican Paraganglioma Study Group. Distinct clinical features of paraganglioma syndromes associated with SDHB and SDHD gene mutations. JAMA. 2004;292:943-51.

7. Lenders JW, Pacak K, Walther MM, Linehan WM, Mannelli M, Friberg $P$, et al. Biochemical diagnosis of Pheochromocytoma which test is best? JAMA 2002; 287(11):1427-34

8. Brink I, Hoegerle S, Klisch J, Biley TA. Imaging of Pheochromocytoma and paraganglioma. Fam Cancer. 2005;4:61-8.

9. Eriksson $B$, Bergström $M$, Sundin A, Juhlin C, Orlefors $\mathrm{H}$, Oberg $\mathrm{K}$, et al. The role of PET in localization of neuroendocrine and adrenocortical tumors. Ann N Y Acad Sci. 2002;970:159-69.

10. Lebuffe G, Dosseh ED, Tek G, Tytgat H, Moreno $\mathrm{S}$, Tavernier B, et al. The effect of calcium channel blockers on outcome following surgical treatment of pheochromocytomas and paragangliomas. Anaesthesia. 2005;60:439-44.

\section{How to cite this article ?}

Kota SK, Kota SK, Jammula S, Panda S. Extra-Adrenal Paraganglioma: An Uncommon Cause of Secondary Hypertension in a Young Subject. J Nepal Paediatr Soc 2011;31(3):238-240. 